\title{
Modulation of Salmonella gene expression by subinhibitory concentrations of quinolones
}

\author{
Grace Yim $^{1}$, JoAnn McClure ${ }^{2}$, Michael G Surette ${ }^{2,3}$ and Julian E Davies ${ }^{1}$
}

Approximately $2.7 \%$ of a collection of Salmonella enterica var. Typhimurium promoter-lux reporter strains showed altered transcriptional patterns when exposed to low concentrations of nine different fluoroquinolones (FQs). Even at the subinhibitory concentrations employed, all nine FQs upregulated genes involved in the SOS response, umuD, lexA, sbmC and $\operatorname{dinP}$. In addition, transcriptional regulators, genes putatively associated with membrane integrity (spr), virulence (sicA) and metabolism $(p / s B)$ were affected. Using the Ames test with Salmonella strain TA102, increased mutagenicity was demonstrated in response to all the FQs tested: ciprofloxacin, moxifloxacin, levofloxacin and gatifloxacin. Transcriptional effects were largely specific to the $\mathrm{FQ}$ antimicrobials. Such responses are consistent with the primary mechanism of action of this class of inhibitor, namely, the introduction of DNA damage. This work provides support for the notion that small molecules can have functions other than growth inhibition that may affect the establishment and maintenance of community dynamics in complex environments. The Journal of Antibiotics (2011) 64, 73-78; doi:10.1038/ja.2010.137; published online 24 November 2010

Keywords: bacterial gyrase; fluoroquinolone; Salmonella; small molecule; SOS response; subinhibitory; transcription

\section{INTRODUCTION}

The fluoroquinolones (FQs) are broad-spectrum, synthetic antimicrobials that are widely used for the treatment of hospital and community infections. They inhibit DNA replication and synthesis by stabilizing a reaction intermediate that contains the FQ, a type II topoisomerase (DNA gyrase and/or DNA topoisomerase IV) and broken DNA. ${ }^{1}$ The type II topoisomerases mediate the passage of one region of duplex DNA through another; interference of this process results in the accumulation of double-stranded DNA breaks and eventually cell death. ${ }^{1}$ Nalidixic acid is generally considered the first generation of these molecules, all other quinolones or 4-quinolones are a derivative of this molecule. FQs have undergone many synthetic improvements, creating potent antimicrobials with broader activity spectra, more favorable pharmacological properties such as extended half-life, increased absorption into human cells and better activity against resistant strains. ${ }^{1}$

Many bacteria, including Salmonella and Escherichia coli, are able to mount a response to DNA damage or stalled DNA replication called the SOS response. This involves more than 30 genes, which allow bacteria to increase DNA damage tolerance and DNA repair. ${ }^{2}$ The LexA protein is the major SOS response regulator that functions as a transcription repressor until DNA damage activates RecA; RecA mediates the autodigestion of LexA, allowing expression of the SOS genes. Members of the SOS regulon include umuDC, $\operatorname{rec} A, \operatorname{lex} A$, $u v r A$ and $\operatorname{din} B .{ }^{2,3}$ Repair of DNA often comes at the cost of mutagenesis. UmuD ${ }_{2} \mathrm{C}$ is a DNA polymerase (Pol V) involved in error-prone repair of DNA and the $\mathrm{UmuD}_{2}{ }_{2} \mathrm{C}$ heterodimer is able to traverse lesions in the DNA that would otherwise block replication, and allows cells to survive when DNA is damaged. The genes encoded by the $u v r A B C$ operon encode an endonuclease that initiates repair of bulky DNA lesions such as the pyrimidine dimers caused by UV radiation. ${ }^{3} \mathrm{DinB}$ (Pol IV) is, like $\mathrm{UmuD}_{2}^{\prime} \mathrm{C}$, a translesion DNA polymerase which is mutagenic. ${ }^{2}$ Many studies have shown that nalidixic acid and older quinolones stimulate some of the genes involved in the bacterial SOS stress response as sequelae of cellular DNA damage. ${ }^{3-5}$

As a continuation of our interest in bacterial responses to subinhibitory levels of small molecules, we show here that sub-MIC levels of older and newer FQs induce significant transcriptional responses in S. enterica serovar Typhimurium (S. typhimurium) ATCC strain 14028. The genes modulated by these antimicrobials are not only strongly associated with bacterial stress functions but also influence virulence and metabolism. This is consistent with the hypothesis that small bioactive molecules, natural or synthetic, depending on their concentration, may have growth inhibitory activity and/or other functions in the environment.

Note that 'true' antibiotics are chemical substances derived from microorganisms which inhibit growth or kill other microorganisms at low concentrations. The fluoroquinolones are technically antimicrobial agents, but as with other synthetic compounds, they perform antibiotic functions in therapy.

${ }^{1}$ Department of Microbiology and Immunology, University of British Columbia, Vancouver, British Columbia, Canada; ${ }^{2}$ Department of Microbiology and Infectious Disease, University of Calgary, Calgary, Alberta, Canada and ${ }^{3}$ Department of Biochemistry and Molecular Biology, University of Calgary, Calgary, Alberta, Canada

Correspondence: Dr JE Davies, Department of Microbiology and Immunology, Life Sciences Institute, University of British Columbia, 4350 Health Sciences Mall, Vancouver, British Columbia, Canada V6T 1 Z3.

E-mail: jed@interchange.ubc.ca

Dedicated to the late $\operatorname{Dr} \mathrm{C}$ Richard Hutchinson for his exceptional contributions to natural product biosynthesis, engineering, and drug discovery.

Received 30 September 2010; accepted 19 October 2010; published online 24 November 2010 


\section{MATERIALS AND METHODS}

\section{Liquid media assay for identifying promoters activated by} fluoroquinolones

As previously described, ${ }^{6}$ a random promoter library was constructed by cloning partially Sau3A-digested S. typhimurium strain 14028 genomic DNA into the reporter vector, pCS26, upstream of a promoterless luxCDABE operon. Eight plates (3072 clones) from a 17-plate library were cultured aerobically at $37^{\circ} \mathrm{C}$ in Luria Bertani (LB) broth containing kanamycin $(\mathrm{Km})$ at $25 \mu \mathrm{g} \mathrm{ml}^{-1}$. After overnight growth, a 384-pin replicator (V\&P Scientific, San Diego, CA, USA) was used to inoculate the 384-well assay plates (Nalge Nunc, Rochester, NY, USA) containing LB supplemented with $\mathrm{Km} 25 \mu \mathrm{g} \mathrm{ml}^{-1}$ and one of the following nine quinolone antibiotics: ciprofloxacin, fleroxacin, grepafloxacin, norfloxacin, gatifloxacin, pefloxacin (perfloxacin), moxifloxacin, enoxacin and levofloxacin (see Table 1 for concentrations of FQs used). The 384 plates were covered with mylar plate sealers (Thermo Electron, Milford, MA, USA) and incubated at $37^{\circ} \mathrm{C}$ without shaking. Light production (counts per second) was measured in a Victor II Multi-label Counter (Perkin-Elmer, Waltham, MA, USA) at 6 and $24 \mathrm{~h}$. Clones showing a differential expression of three times or greater were re-arrayed into 384 well plates and re-screened in the same manner. Clones still showing a differential expression of three times or greater were chosen and re-arrayed into 96-well plates (Nalge Nunc), and re-screened a second time in the same manner. Consistently positive clones were streaked onto LB agar supplemented with $50 \mu \mathrm{g} \mathrm{ml}^{-1} \mathrm{Km}$. Two colonies of each clone were screened for a third time measuring light production and growth (OD at $620 \mathrm{~nm}$ ) at 2, 4, 6 and $24 \mathrm{~h}$. Colonies from positive clones were PCR amplified using the primers PZE05 (5'-CCAGCTGGCAATTCCGA- $3^{\prime}$ ) and PZE06 (5'-AATCATCACTTTCGGGAA- ${ }^{\prime}$ ). The PCR products were cleaned with a QIAquick PCR Purification Kit (Qiagen, Mississauga, ON, Canada) and sequenced in both directions using the primers PZE05 and PZE06. Annotation and identification of DNA sequences was conducted by comparison of sequences to the GenBank database using the NCBI BLASTN program (http://blast.ncbi.nlm.nih.gov/BLAST/cgi.), and analyzed using VECTOR NTI software (Informax, Bethesda, MD, USA).

\section{Solid media assays}

Promoter clones showing an FQ response in liquid media were grown aerobically overnight in LB with $50 \mu \mathrm{g} \mathrm{ml}^{-1} \mathrm{Km}$ at $30^{\circ} \mathrm{C}$. The cultures were diluted by 10 -fold and $75 \mu \mathrm{l}$ spread on LB agar plates containing $50 \mu \mathrm{g} \mathrm{ml}^{-1}$ $\mathrm{Km}$. Alternatively, overnight cultures were spread using cotton swabs. FQs were spotted on to $6 \mathrm{~mm}$ filter paper discs (Advantec, Tokyo, Japan), placed on the agar and incubated at $37^{\circ} \mathrm{C}$ overnight. Luminescence was detected using a LB980 camera (EG\&G Berthold, Oak Ridge, TN, USA).

\section{Specificity of response to FQs and stress-response triggers}

FQ positive clones were screened for responses to other antibiotics at subinhibitory concentrations: rifampicin $\left(1 \mu \mathrm{g} \mathrm{ml}^{-1}\right)$, erythromycin $\left(5 \mu \mathrm{g} \mathrm{ml}^{-1}\right)$, azithromycin $\left(0.31 \mu \mathrm{g} \mathrm{ml}^{-1}\right)$, lincomycin $\left(6.25 \mu \mathrm{g} \mathrm{ml}^{-1}\right)$, pristinamycin

Table 1 The MIC of FQ antibiotics used in this study and their respective abbreviations

\begin{tabular}{lccc}
\hline Antibiotic & MIC $\left(\mu \mathrm{gm}^{-1}\right)$ & Concentration used $\left(\mu{\mathrm{g} \mathrm{I}^{-1}}^{-}\right)$ & Generation $^{1}$ \\
\hline Ciprofloxacin (cip) & 0.05 & 0.01 & 2nd \\
Enoxacin (enox) & 0.35 & 0.05 & 2nd \\
Fleroxacin (fler) & 0.20 & 0.03 & 2nd \\
Norfloxacin (norf) & 0.35 & 0.05 & $2 \mathrm{nd}$ \\
Perfloxacin (per) & 0.25 & 0.05 & $2 \mathrm{nd}$ \\
Gatifloxacin (gati) & 0.05 & 0.01 & $3 \mathrm{rd}$ \\
Grepafloxacin (grep) & 0.10 & 0.03 & $3 \mathrm{rd}$ \\
Levofloxacin (levo) & 0.08 & 0.01 & $3 \mathrm{rd}$ \\
Moxifloxacin (moxi) & 0.20 & 0.05 & $3 \mathrm{rd}$ \\
\hline
\end{tabular}

Abbreviation: $F Q$, fluoroquinolones. $\left(1.25 \mu \mathrm{g} \mathrm{ml}^{-1}\right)$, telithromycin $\left(1.25 \mu \mathrm{g} \mathrm{ml}^{-1}\right)$, tylosin $\left(6.25 \mu \mathrm{g} \mathrm{ml}^{-1}\right)$ and chloramphenicol $\left(0.05 \mu \mathrm{g} \mathrm{ml}^{-1}\right)$. Assays were conducted in 96-well plates as described above, with measurements of CPS and $\mathrm{OD}_{620}$ taken at 2, 4, 6 and $24 \mathrm{~h}$. In addition, agar plate assays were used to determine specificity of antibiotic responses with ampicillin, erythromycin or rifampicin sensitivity discs.

The FQ positive clones were also screened for responses to membrane, osmotic and DNA damage stress on solid medium. Paper discs with $15 \mu \mathrm{l}$ of the following compounds were used in such assays: 10\% SDS, 100\% Triton X, $25 \mathrm{mg} \mathrm{m}^{-1}$ ampicillin, 10\% deoxycholate, 95\% EtOH, 95\% butanol, $10 \mathrm{mg} \mathrm{ml}^{-1}$ ethidium bromide, $5 \mathrm{M} \mathrm{NaCl}$ and $50 \mathrm{mg} \mathrm{ml}^{-1}$ chloroquine. Liquid assays were conducted using the following concentrations: SDS $(0.005 \%)$, EtOH $(0.1 \%)$, Triton X $(0.001 \%)$, ampicillin $\left(0.5 \mu \mathrm{g} \mathrm{ml}^{-1}\right)$, butanol $(0.1 \%)$, deoxycholate $(0.01 \%)$, ethidium bromide $\left(500 \mu \mathrm{g} \mathrm{m}^{-1}\right), \mathrm{NaCl}(0.5 \mathrm{M})$ and chloroquine $\left(10 \mu \mathrm{g} \mathrm{ml}^{-1}\right)$.

\section{Mutagenicity assay}

Quantitative mutagenicity plate assays were performed using S. typhimurium strain TA102 [his $\Delta(G) 8476 \mathrm{rfa} / \mathrm{pAQ} 1 / \mathrm{pKM} 101]$ without the use of $\mathrm{S} 9$ activation mix as described by Maron and Ames. ${ }^{7}$ Concentrated stock solutions were made with DMSO, diluted with water and water used as the solvent control.

\section{RESULTS}

\section{Identification of FQ-responsive promoters}

To identify trends in the responses to sub-MIC FQs, a subset of the S. typhimurium 14028 random lux promoter reporter library was screened at 6 and $24 \mathrm{~h}$, as described previously for erythromycin and rifampicin, ${ }^{6}$ against nine different FQs (Table 1). The 567 clones showing at least a threefold increase or decrease of expression relative to the no antibiotic control were re-screened three times to yield a final set of 83 promoters, approximately $2.7 \%$ of clones tested.

Expression in response to a given FQ was both highly up- and downregulated; expression in the presence of a representative FQ, grepafloxcin is shown in Figure 1a. Expression in the presence of grepafloxacin ranged from 37 -fold upregulation for $u m u D$ to 17 -fold downregulation of sopA relative to the control (Figure 1b). For a given gene, the magnitude of the response varied depending on the FQ used; the gene, $\operatorname{sbm} C$, showed a 2.5 -fold increase in expression in the presence of flerofloxacin and a 16-fold increase in the presence of moxifloxacin. Most genes were regulated similarly by all nine FQs, few of the active clones being responsive to a single FQ (Table 2). Strong responses of some promoters were seen, especially in the cases of ciprofloxacin, grepafloxacin and moxifloxacin (Figure 1b). This may be a reflection of optimal FQ concentrations for transcription modulation being used in liquid screens for ciprofloxacin, grepafloxacin and moxifloxacin and not other FQs. This is consistent with the observation that clones responsive to a subset of antibiotics in liquid were responsive to all FQs on solid media (Figure 2). On solid media, there is a gradient of antibiotic concentrations present on a given agar plate; whereas in liquid culture, only one concentration is present which may not be the optimal concentration for activation of expression.

\section{FQ-responsive promoters involved in stress response}

The stress response genes (umuD, $\operatorname{lex} A, \operatorname{din} P$ and $s b m C$ ) were upregulated by all nine FQs tested. DNA damage created by quinolone antibiotics has been shown to be sufficient to stimulate $u m u C$ transcription and the SOS response. ${ }^{4,5}$ The initial response to DNA damage is the reduction in LexA protein levels and induction of LexA repressed genes, which include lexA, umuDC and $\operatorname{din} P^{2,3}$ (In Escherichia. coli, $\operatorname{din} B$ and $\operatorname{din} P$ are two names for one gene, there is no $\operatorname{din} B$ in $S$. typhimurium. ${ }^{8}$ ) The $\operatorname{sbmC}$ gene was originally 

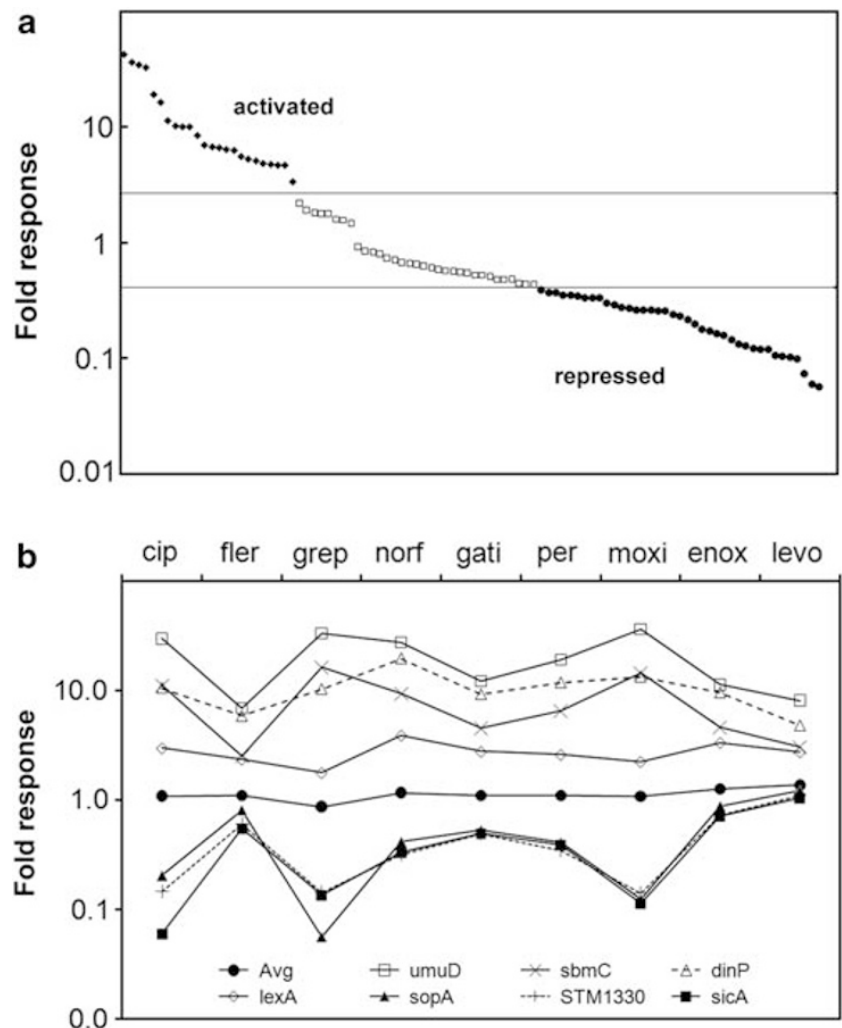

Figure 1 (a) The fold change of expression for grepafloxacin-activated and -repressed clones shown with 33 'negatives'. (b) Fold change in expression in response to nine different FQs. Avg represents the mean fold change in expression for all 3072 clones in the original screen.

identified by its ability to confer resistance to MccB17 at high copy number. ${ }^{9}$ MccB17 is a peptide antibiotic that induces double-stranded breaks in DNA in a DNA gyrase-dependent manner. ${ }^{9}$ In E.coli, the expression of $s b m C$ is induced by DNA-damaging agents, possesses a quasicanonical LexA box and much like $u m u D C$, the expression of $s b m C$ is RecA and LexA dependent. ${ }^{9}$ Thus, upregulation of $u m u D$, $\operatorname{lexA} \operatorname{din} P$ and $\operatorname{sbm} C$ by all nine FQs is likely LexA dependent. Figure $1 \mathrm{~b}$ shows some of the more responsive clones as well as those related to the SOS response.

\section{FQ-responsive promoters unrelated to SOS response}

In addition to effects on stress response, a variety of other functions were modulated by sub-MIC FQs. Analysis of 83 PCR products obtained from the responsive promoter clones (Table 2) suggested that FQs also affect the transcription of genes putatively involved in virulence ( $s i c A)$, metabolism ( $p l s B$ ) and chemotaxis (STM3138).

Interestingly, the gene encoding $\mathrm{H}-\mathrm{NS}$, and two other putative DNA-binding proteins, were affected by sub-MIC FQs (Table 2). $\mathrm{H}-\mathrm{NS}$ is a small, abundant, nucleoid-associated protein implicated in chromosomal organization of DNA. H-NS has been shown to control the expression of several genes of the $\sigma^{\mathrm{s}}$ regulon in E. coli, ${ }^{10}$ as well as genes encoding the synthesis of cell envelope components or associated proteins. ${ }^{11}$ Our studies suggest that many genes encoding membrane-associated proteins were affected by FQs (Table 2), these are perhaps mediated by H-NS. Induction of $s b m C$ by DNA damage is positively regulated by $\mathrm{H}-\mathrm{NS}$ binding, ${ }^{12}$ suggesting $s b m C$ induction by FQs is H-NS and LexA mediated. As H-NS is regulated by DNA supercoiling, ${ }^{10}$ the accumulation of double-strand breaks and the resulting decrease in DNA supercoiling may explain altered H-NS expression.

Specificity of FQ-transcription responses: comparison of FQs, various antibiotics and known stress-response triggers

Several genes involved in SOS response, umuD and lexA, were examined on solid media. FQs had similar effects on both reporter strains in liquid and solid media, showing activation by most FQs in liquid media (Figure 1b) and activation by all FQs on solid media (Figure 2). When the $u m u D$ reporter strain was exposed to antibiotics (bioactive small natural molecules), the $u m u D$ reporter strain responded to all FQs but not to erythromycin, rifampicin or chloramphenicol (Figure 2a). The luminescence response to pefloxacin and fleroxacin was weaker than the other FQs and may reflect a reduced ability to induce the SOS response. The lexA promoter responded to all the FQs and more strongly to rifampicin, but not to erythromycin and chloramphenicol (Figure 2b).

FQ-responsive promoters were screened against various antibiotics to determine how specific the FQ response was. Liquid culture assays indicated that, for most part, the expression of this set of promoters was modulated exclusively by the FQs (not shown). A few exceptions included 7-B13 (pckA), which is downregulated by rifampicin, and 5-K04 (STM1810), which was downregulated by the macrolide tylosin. Solid media assays showed that 4-E18 (plsB) and 5-H21 (hns) were upregulated by rifampicin and ampicillin. Seven other clones (not sequenced) were also transcriptionally upregulated by rifampicin; however, the majority of the clones remained unaffected by other antibiotics.

The expression of these promoters in the presence of compounds that trigger known stress responses was also investigated. Disc diffusion assays were carried out with selected promoters employing chemicals that trigger membrane, DNA damage and osmotic stress: SDS, Triton X, deoxycholate, ethanol, butanol, ethidium bromide and $\mathrm{NaCl}$ (data not shown). The majority of these stressors failed to produce a zone of growth inhibition and did not induce luminescence, with the exception of butanol, which had a zone of inhibition but was still unable to activate transcription.

\section{FQ-induced mutagenicity}

As the SOS response was induced by all FQs tested, the rate of mutagenesis should also increase in response to these compounds. Using the Ames test, several of the older second generation FQs such as ciprofloxacin, enoxacin, oflaxacin, norfloxacin, etc. had been shown to induce mutagenicity in $S$. typhimurium. ${ }^{4,5,13}$ However, increases in mutagenicity had not been shown for the newer third generation FQs. At nongrowth inhibitory levels, all the FQs tested in the Ames test increased the mutagenicity of S. typhimurium TA102 (Table 3). This increase in mutagenicity was consistent with the increase in $u m u D$ and lexA expression observed with all FQs tested (Figure 2).

\section{DISCUSSION}

We have shown previously that antibiotics at low concentrations modulate global transcription patterns in bacteria and proposed that this property is associated with their function as environmental signaling agents. Extensive studies with subinhibitory concentrations of a variety of antibiotic substances, including inhibitors of translation (macrolides ${ }^{14}$ ), transcription (rifampicin ${ }^{6,15}$ ), and cell wall inhibitors (imipenem ${ }^{6}$ ) showed a wide range of dose-dependent transcription responses in S. typhimurium, as measured by the use of promoter-lux reporter libraries. Many different genes were activated or repressed, 
Table 2 FQ-responsive clones identified from screening a S. typhimurium random promoter library

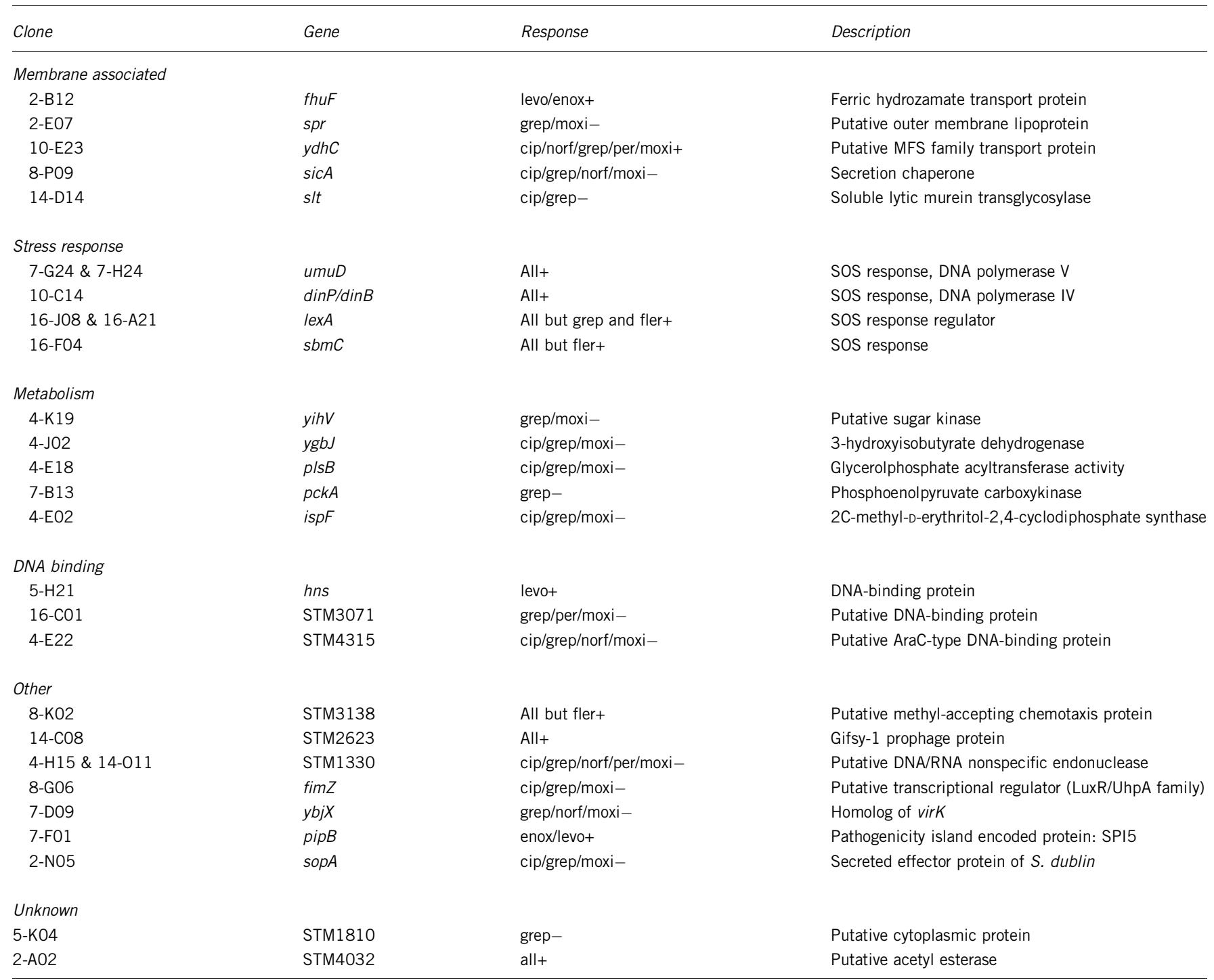

Abbreviations: cip, ciprofloxacin; enox, enoxacin; fler, fleroxacin; gati, gatifloxacin; grep, grepafloxacin; levo, levofloxacin; moxi, moxifloxacin; norf, norfloxacin; per, perfloxacin; S. typhimurium, Salmonella typhimurium.

' - ' indicates the gene was downregulated by the respective compound(s) and ' + ' indicates the gene was upregulated by the respective compound(s).

including virulence, metabolism, adaptive functions, transport and genes of unknown function. ${ }^{6,14,15}$ Mutations in regulatory and stress response genes did not have significant effects on sub-MIC-induced modulation; these responses were attenuated in antibiotic-resistant mutants, suggesting that the target of growth inhibitory action was involved in transcription modulation. ${ }^{6,16}$ We also demonstrated that different classes of antibiotics modulated distinct sets of promoters. ${ }^{6}$ These findings led to the suggestion that detection and classification of pharmaceutically active compounds might be possible by monitoring transcription of selected promoter clones. ${ }^{6}$ The transcription response pattern from an unknown compound could be compared with a reference library of transcriptome or proteome expression profiles from a bacteria treated with different classes of antibiotics. On the basis of the assumption that compounds with similar profiles may have similar modes of action, the mode of action of several small molecules was identified or reclassified. ${ }^{17,18}$ As reporter strains respond to compounds at nongrowth inhibitory concentration, this allows the detection of bioactive compounds that may be overlooked by traditional screening methods employing growth inhibition of tester organisms. Conversely, mode of action panels can be used to identify novel producer organisms from collections of supernatants, as was done with streptonigrin and novobiocin producers. ${ }^{19}$ This work is consistent with other studies showing that many bioactive small molecules mediate bacterial transcriptional responses at subinhibitory concentrations. ${ }^{20}$

The FQ antimicrobials have essential roles in the therapy of infectious diseases and are one of the most widely-used classes of drugs. In one sense, because of their specificity of target and the respective resistance mechanisms that develop in response to therapy, they act like natural products. Natural compounds such as the coumarins (novobiocin, etc.) inhibit in a mechanistically distinct manner, blocking bacterial DNA replication by binding to the $\mathrm{B}$ subunit of bacterial DNA gyrase and inhibiting ATPase activity; ${ }^{21}$ this affects DNA supercoiling but does not create double-stranded breaks. ${ }^{22}$ Mitomycin C, another natural product, is a classical inducer used in the study of the SOS response, ${ }^{3}$ which damages DNA by 


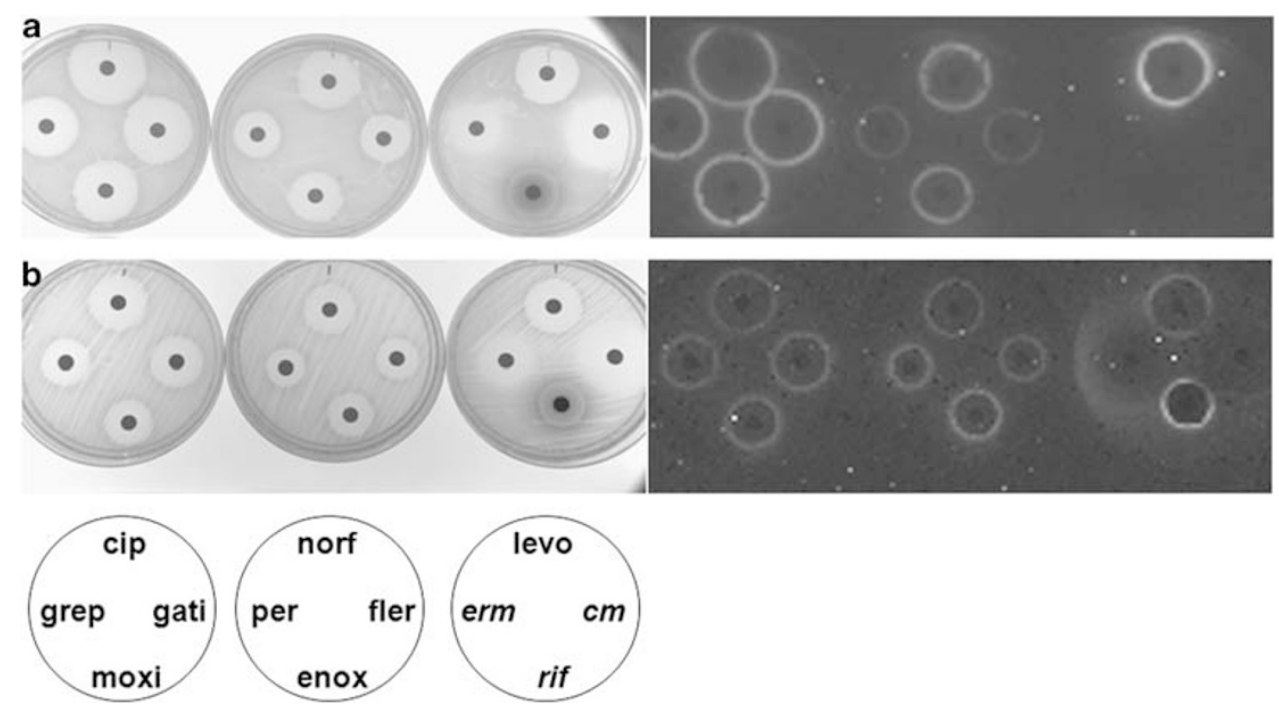

Figure 2 Responsiveness of selected promoters to FQs on solid media. The response of strains containing umuD (a) and lexA (b) I luxCDABE reporter fusions to FQs (as abbreviated in Table 1), erythromycin (erm), rifampicin (rif) and chloramphenicol (cm) containing disks. Left side panels are photographs of the plates taken under white light illumination. Panels on the right side represent light produced from the promoter fusions.

Table 3 Reversion of S. typhimurium strain TA102 by FQs

\begin{tabular}{lcl}
\hline & $\begin{array}{c}\text { Amount } \\
\text { (ng per plate) }\end{array}$ & Colonies \\
\hline Solvent control (water) & - & $180 \pm 50$ \\
Ciprofloxacin & 6.3 & $420 \pm 180$ \\
& 25 & $440 \pm 190$ \\
Gatifloxacin & 100 & $130 \pm 60$ \\
& 3.1 & $200 \pm 100$ \\
Levofloxacin & 12.5 & $710 \pm 280$ \\
& 50 & $320 \pm 120$ \\
Moxifloxacin & 10 & $590 \pm 90$ \\
& 40 & $290 \pm 80$ \\
& 160 & $130 \pm 70$ \\
& 6.3 & $180 \pm 70$ \\
& 25 & $600 \pm 210$ \\
& 100 & $180 \pm 140$
\end{tabular}

Abbreviations: FQ, fluoroquinolones; S. typhimurium, Salmonella typhimurium.

inducing DNA cross-linking. ${ }^{23}$ Although clinically used FQs are synthetic, quinolones occur naturally and a variety of related microbial compounds have been identified with diverse activities such as quorum sensing (Pseudomonas quinolone signal), ${ }^{24}$ siderophores (quinolobactin), ${ }^{25}$ inhibitors of cytochrome $b c_{1}$ complex, ${ }^{25}$ etc. Similarly, although synthetic chemicals, bacterial resistance to FQs is as ubiquitous as resistance to natural products (antibiotics) and is also genetically transferable. ${ }^{26}$ Our demonstration that FQs act principally on stress-related operons is clearly related to their ability to damage DNA; our studies show that the transcription of genes related to DNA damage is induced even at subinhibitory concentrations.

This work also shows that virulence genes are upregulated by subMIC FQs. Exposure of S. typhimurium, E. coli or P. aeruginosa to subMIC quinolones affect cell size, pilus, fimbriae production and cell adherence. $^{27-29}$ Low concentrations of quinolones also increase the production of virulence factors such as verotoxin encoding bacteriophage and verotoxin from E. coli O157:H7..$^{30-32}$ We also identified modulation of other virulence-associated genes, including $p i p B$, a pathogenicity island (SPI5)-encoded protein, $y b j X$, a homolog of $v i r K$ and fim $Z$, a LuxR/UhpA family transcriptional regulator of fimbriae production. Many virulence genes are phage-associated. S. typhimurium ATCC 14028 has three fully functional phages, Gifsy-1, 2 and 3, which contain sequences with similarity to known Salmonella virulence genes. ${ }^{33,34}$ Furthermore, sub-MIC ciprofloxacin and pefloxacin were shown to induce a prophage of S.typhimurium. ${ }^{35}$ In the present work, STM2623, encoding a Gifsy-1 prophage protein, was upregulated by sub-MIC levels of all nine FQs (Table 2). Enhanced virulence in the presence of FQs treatment may ${ }^{36}$ or may not ${ }^{37}$ be explained by the SOS induction of phage genes.

Numerous studies have demonstrated the myriad of effects elicited by FQs in a variety of different bacterial genera. ${ }^{16,38,39}$ These effects include increased mutagenicity (transient), ${ }^{39}$ phage induction and its sequelae (virulence), enhanced adhesion, integron cassette recombination $^{40}$ and others. ${ }^{38}$ It is well-established that antimicrobial/antibacterial pressure can select for either resistant cells or cells with an increased mutation/recombination rate, permanently becoming hypermutators. ${ }^{39}$ Our studies indicate that the older as well as newer FQs, such as moxifloxacin, levofloxacin and gatifloxacin, strongly induce transient mutagenic mechanisms such as the SOS response. The multiple effects, mutagenic and otherwise, of sub-MIC FQs can be explained by the predominant activity of FQs as activators of stress response. Recent studies have presented an interesting twist to mixed culture population dynamics; when antibiotic-resistant and susceptible E. coli are grown in mixed culture, highly resistant cells will release the molecule indole, signaling to antibiotic susceptible sister cells to turn on efflux pumps and oxidative stress protective mechanisms to aid in the survival of the entire population. ${ }^{41}$ As all these effects occur at non-lethal drug concentrations, it can be predicted that a significant variety of unsuspected effects may occur during the course of FQ therapy. In particular, our studies have relevance in the light of two recent publications by Dethlefsen et al., ${ }^{42,43}$ describing the 'pervasive' effects of the administration of therapeutic concentrations of ciprofloxacin on the human gut microbiome. This work showed that administration of this FQ disrupts the stable state of the microbial population. Given that FQs are potent broad-spectrum antimicrobials, they would be expected to induce permanent behavioral changes in 
many members of the gut microbiota with wide-reaching consequences in health and disease.

\section{ACKNOWLEDGEMENTS}

FQs not available from Sigma Aldrich (St Louis, MO, USA) were gifts to JED. Strain TA102 was kindly provided by Dr TJ Schrader (Health Canada, Ottawa, Canada). This work was supported by grants from the Canadian Institutes of Health Research and the Canadian Bacterial Disease Network to MGS and JED. We also thank the Natural Sciences and Engineering Research Council of Canada for funding to JED and GY and the support of the Li Tze Fong Memorial Fellowship to GY.

1 Hooper, D. C. \& Rubinstein, E. Quinolone Antimicrobial Agents, 3rd ed. (ASM Press, Washington, DC, 2003).

2 Sutton, M. D., Smith, B. T., Godoy, V. G. \& Walker, G. C. The SoS response: recent insights into umuDC-dependent mutagenesis and DNA damage tolerance. Annu. Rev. Genet. 34, 479-497 (2000).

3 Walker, G. C. Mutagenesis and inducible responses to deoxyribonucleic acid damage in Escherichia coli. Microbiol. Rev. 48, 60-93 (1984)

4 Ysern, P. et al. Induction of SOS genes in Escherichia coli and mutagenesis in Salmonella typhimurium by fluoroquinolones. Mutagenesis. 5, 63-66 (1990).

5 Power, E. G. \& Phillips, I. Correlation between umuC induction and Salmonella mutagenicity assay for quinolone antimicrobial agents. FEMS Microbiol. Lett. 112, 251-254 (1993).

6 Goh, E. B. et al. Transcriptional modulation of bacterial gene expression by subinhibitory concentrations of antibiotics. Proc. Natl Acad. Sci. USA 99, 17025-17030 (2002).

7 Maron, D. M. \& Ames, B. N. Revised methods for the Salmonella mutagenicity test. Mutat. Res. 113, 173-215 (1983).

$8 \mathrm{Kim}, \mathrm{S}$. R. et al. Multiple pathways for SOS-induced mutagenesis in Escherichia coli: an overexpression of $\operatorname{din} \mathrm{B} / \mathrm{din} \mathrm{P}$ results in strongly enhancing mutagenesis in the absence of any exogenous treatment to damage DNA. Proc. Natl Acad. Sci. USA 94, 13792-13797 (1997).

9 Baquero, M. R., Bouzon, M., Varea, J. \& Moreno, F. sbmC, a stationary-phase induced SOS Escherichia coli gene, whose product protects cells from the DNA replication inhibitor microcin B17. Mol. Microbiol. 18, 301-311 (1995).

10 Barth, M., Marschall, C., Muffler, A., Fischer, D. \& Hengge-Aronis, R. Role for the histone-like protein $\mathrm{H}$-NS in growth phase-dependent and osmotic regulation of sigma $\mathrm{S}$ and many sigma S-dependent genes in Escherichia coli. J. Bacteriol. 177, 34553464 (1995).

11 Hommais, F. et al. Large-scale monitoring of pleiotropic regulation of gene expression by the prokaryotic nucleoid-associated protein, H-NS. Mol. Microbiol. 40, 20-36 (2001).

12 Oh, T. J., Jung, I. L. \& Kim, I. G. The Escherichia coli SOS gene sbmC is regulated by HNS and RpoS during the SOS induction and stationary growth phase. Biochem. Biophys. Res. Commun. 288, 1052-1058 (2001).

13 Mamber, S. W., Kolek, B., Brookshire, K. W., Bonner, D. P. \& Fung-Tomc, J. Activity of quinolones in the Ames Salmonella TA102 mutagenicity test and other bacterial genotoxicity assays. Antimicrob. Agents Chemother. 37, 213-217 (1993).

14 Tsui, W. H. et al. Dual effects of MLS antibiotics: transcriptional modulation and interactions on the ribosome. Chem. Biol. 11, 1307-1316 (2004).

15 Yim, G., de la Cruz, F., Spiegelman, G. B. \& Davies, J. Transcription modulation of Salmonella enterica serovar Typhimurium promoters by sub-MIC levels of rifampin. J. Bacteriol. 188, 7988-7991 (2006).

16 Mesak, L. R., Miao, V. \& Davies, J. Effects of subinhibitory concentrations of antibiotics on SOS and DNA repair gene expression in Staphylococcus aureus. Antimicrob. Agents Chemother. 52, 3394-3397 (2008).

17 Hutter, B. et al. Prediction of mechanisms of action of antibacterial compounds by gene expression profiling. Antimicrob. Agents Chemother. 48, 2838-2844 (2004).

18 Freiberg, C. \& Brotz-Oesterhelt, H. Functional genomics in antibacterial drug discovery. Drug Discov. Today 10, 927-935 (2005).
19 Mesak, L. R., Qi, S., Villanueva, I., Miao, V. \& Davies, J. Staphylococcus aureus promoter-lux reporters for drug discovery. J. Antibiot. (Tokyo). 63, 492-498 (2010).

20 Yim, G., Huimi Wang, H. \& Davies, J. The truth about antibiotics. Int. J. Med. Microbiol. 296, 163-170 (2006)

21 Gormley, N. A., Orphanides, G., Meyer, A., Cullis, P. M. \& Maxwell, A. The interaction of coumarin antibiotics with fragments of DNA gyrase B protein. Biochemistry. 35, 5083-5092 (1996).

22 Gmuender, H. et al. Gene expression changes triggered by exposure of Haemophilus influenzae to novobiocin or ciprofloxacin: combined transcription and translation analysis. Genome Res. 11, 28-42 (2001).

23 Tomasz, M. Mitomycin C: small, fast and deadly (but very selective). Chem. Biol. 2, 575-579 (1995).

24 Diggle, S. P., Cornelis, P., Williams, P. \& Camara, M. 4-quinolone signalling in Pseudomonas aeruginosa: old molecules, new perspectives. Int. J. Med. Microbiol. 296, 83-91 (2006).

25 Heeb, S. et al. Quinolones: from antibiotics to autoinducers. FEMS Microbiol. Rev. (e-pub ahead of print; doi:10.1111/j.1574-6976.2010.00247.x) (2010).

26 Strahilevitz, J., Jacoby, G. A., Hooper, D. C. \& Robicsek, A. Plasmid-mediated quinolone resistance: a multifaceted threat. Clin. Microbiol. Rev. 22, 664-689 (2009).

27 Sonstein, S. A. \& Burnham, J. C. Effect of low concentrations of quinolone antibiotics on bacterial virulence mechanisms. Diagn. Microbiol. Infect. Dis. 16, 277-289 (1993).

28 Vranes, J., Zagar, Z. \& Kurbel, S. Influence of subinhibitory concentrations of ceftazidime, ciprofloxacin and azithromycin on the morphology and adherence of Pfimbriated Escherichia coli. J. Chemother. 8, 254-260 (1996).

29 Majtan, J., Majtanova, L., Xu, M. \& Majtan, V. In vitro effect of subinhibitory concentrations of antibiotics on biofilm formation by clinical strains of Salmonella enterica serovar Typhimurium isolated in Slovakia. J. Appl. Microbiol. 104, 1294-1301 (2008).

30 Zhang, X. et al. Quinolone antibiotics induce Shiga toxin-encoding bacteriophages, toxin production, and death in mice. J. Infect. Dis. 181, 664-670 (2000).

31 Yoh, M., Frimpong, E. K., Voravuthikunchai, S. P. \& Honda, T. Effect of subinhibitory concentrations of antimicrobial agents (quinolones and macrolide) on the production of verotoxin by enterohemorrhagic Escherichia coli 0157:H7. Can. J. Microbiol. 45, 732-739 (1999).

32 Grif, K., Dierich, M. P., Karch, H. \& Allerberger, F. Strain-specific differences in the amount of Shiga toxin released from enterohemorrhagic Escherichia coli 0157 following exposure to subinhibitory concentrations of antimicrobial agents. Eur. J. Clin. Microbiol. Infect. Dis. 17, 761-766 (1998).

33 Figueroa-Bossi, N., Uzzau, S., Maloriol, D. \& Bossi, L. Variable assortment of prophages provides a transferable repertoire of pathogenic determinants in Salmonella. Mol. Microbiol. 39, 260-271 (2001)

$34 \mathrm{Ho}, \mathrm{T}$. D. et al. Identification of GtgE, a novel virulence factor encoded on the Gifsy-2 bacteriophage of Salmonella enterica serovar Typhimurium. J. Bacteriol. 184, 5234-5239 (2002)

35 Majtan, V. \& Majtanova, L. Postantibiotic effects and postantibiotic sub-MIC effects of ciprofloxacin, pefloxacin and amikacin on the biological properties of Salmonella strains. Folia. Microbiol. (Praha). 42, 327-332 (1997).

36 Waldor, M. K. \& Friedman, D. I. Phage regulatory circuits and virulence gene expression. Curr. Opin. Microbiol. 8, 459-465 (2005)

37 Comeau, A. M., Tetart, F., Trojet, S. N., Prere, M. F. \& Krisch, H. M. Phage-antibiotic synergy (PAS): beta-lactam and quinolone antibiotics stimulate virulent phage growth. PLoS One. 2, e799 (2007).

38 Davies, J., Spiegelman, G. B. \& Yim, G. The world of subinhibitory antibiotic concentrations. Curr. Opin. Microbiol. 9, 445-453 (2006).

39 Couce, A. \& Blazquez, J. Side effects of antibiotics on genetic variability. FEMS Microbiol. Rev. 33, 531-538 (2009).

40 Guerin, E. et al. The SOS response controls integron recombination. Science $\mathbf{3 2 4}$ 1034 (2009).

41 Lee, H. H., Molla, M. N., Cantor, C. R. \& Collins, J. J. Bacterial charity work leads to population-wide resistance. Nature 467, 82-85 (2010).

42 Dethlefsen, L., Huse, S., Sogin, M. L. \& Relman, D. A. The pervasive effects of an antibiotic on the human gut microbiota, as revealed by deep 16S rRNA sequencing. PLoS Biol. 6, e280 (2008).

43 Dethlefsen, L. \& Relman, D. A. Microbes and Health Sackler Colloquium: incomplete recovery and individualized responses of the human distal gut microbiota to repeated antibiotic perturbation. Proc. Nat/ Acad. Sci. USA (e-pub ahead of print; doi:10.1073/ pnas.1000087107) (2010). 